\title{
A simple method for estimating a cow's breeding value from her own lactations and her sire's progeny test
}

\author{
M. SCHNEEBERGER and H. EUGSTER \\ Herdebuchstelle fuer Braunvieh, Chamerstrasse 56, CH-6300 Zug, Schweiz
}

A selection index including the cow's own lactations and her sire's progeny test was constructed to estimate routinely cows' breeding values in the Swiss Braunvieh population. Lactation yields are expressed as deviations from 3-year herd averages and corrected for genetic trend. Phenotypic and genetic variances and covariances were computed from progeny of 136 sires by MINQUE. Heritabilities were .16 for first, .13 for second, and .20 for third lactations. Genetic correlations were $.93, .74$ and .95 between first and second, first and third, and second and third lactations. Index weights are presented for various numbers of daughters in the sire's progeny test.

\section{Sire evaluation for FCM yield in Sweden considering the maternal grandsire of the daughter}

\author{
J.A. ERIKSSON and Brigitta DANELL \\ SHS-Association for Swedish Livestock Breeding and Production, \\ $S$-631 84 Eskilstuna, Sweden \\ Dept of Animal Breeding and Genetics, Swedish University of Agricultural Sciences, \\ S-750 07 Uppsala, Sweden
}

Dairy sires of the Swedish Red and White and Swedish Friesian breeds were evaluated for milk yield by two mixed models. The first model included fixed herd-year-seasons and sire group effects and a random sire effect and the second model also considered the maternal grandsire of the cow. The results show that the second model utilized the data more efficiently. A threefold increase in the ties between sires was obtained as well as an increased variation of the predicted differences. The correlations between the evaluations of the models were 0.98-1.00. Negative assortative matings were indicated among selected sires.

\section{Efficiency in milk and calf yield for dairy cows : measurements, environmental factors, genetic parameters}

\author{
R. ALEANDRI*, I. MAO **, A.M. PILLA *** \\ * Associazione Italiana Allevatori, v. Tomassetti 9, 0016I Roma, Italia \\ ** Dept. Animal Science, Michigan State University, E. Lansing, MI 48824, U.S.A. \\ *** Istituto sperimentale per la Zootecnia, v. O. Panvinio 16, 00612 Roma, Italia
}

Two traits expressing dairy cow's outputs per time unit were defined. $\mathrm{CY}=$ (number of days in gestation in a given period) and $M Y=(\mathrm{kgs}$ of milk effectively produced in a given period) were considered measurements, respectively, of the reproductive and productive performances of the dairy cow. The time-unit was assumed equal to one-year and the starting point of the economical lifetime of a dairy cow was the date of the first calving. Environmental factors for CY and MY were defined and analysed using two models both including a covariate term. Least squares solutions were used as additive adjustment factors for the environmental effects. Restricted Maximum Likelihood Method was used to compute genetic parameters estimates for each period. The model included the sire random effect. the sire's origin fixed and the herd fixed effect. 